\title{
Non-invasive approach to treat primary solid solitary pulmonary nodule: a narrative review by the radiation oncologist perspective
}

\author{
Elisa D’Angelo, Chiara Lauro, Laura Rubino, Alessio Bruni^ \\ Radiation Therapy Unit, Department of Oncology and Hematology, University Hospital of Modena, Modena, Italy \\ Contributions: (I) Conception and design: A Bruni, E D’Angelo; (II) Administrative support: None; (III) Provision of study materials or patients: All \\ authors; (IV) Collection and assembly of data: A Bruni, E D'Angelo; (V) Data analysis and interpretation: A Bruni, E D'Angelo; (VI) Manuscript \\ writing: All authors; (VII) Final approval of manuscript: All authors. \\ Correspondence to: Alessio Bruni. Radiation Therapy Unit, Department of Oncology and Hematology, University Hospital of Modena, Modena, Italy. \\ Email: bruni.alessio@aou.mo.it.
}

Objective: The aim of this review is to evaluate the role of stereotactic body radiotherapy (SBRT) in treating solitary lung nodule without pathological confirmation.

Background: Lung cancer is one of the leading causes of cancer death worldwide. Taking into account the increasing number of new diagnoses of solid solitary pulmonary nodules, the issue is to identify when an invasive procedure is needed before planning a radical treatment. The role of SBRT is crucial, particularly in those patients at greater risk of complications after invasive procedures or surgery.

Methods: This review focused on selection criteria of patients submitted to SBRT for solid solitary lung nodules in clinically diagnosed lung cancer. A literature search in Medline was performed until April 2021. Terms used were a combination of "solitary pulmonary nodule", "radiotherapy", "stereotactic body radiotherapy", "pathological confirmation", and "lung". We identified 149 records and 20 studies were selected, analyzed and discussed. All studies but two are retrospective. In 6 studies only patients without pathological confirmation were included, while 14 compared histologically proven and not subgroups. All studies were published between 2009 and 2019. SBRT was used in all except one, even if different doses were administered. SBRT resulted as an efficient treatment with high rates of local control in patients affected by early stage non-small-cell lung cancer (NSCLC), even if overall survival varies greatly depending on different factors (population features, lesion diameter, clinical stage, radiation therapy doses). Three-year local control was higher than $75 \%$ in all studies in which it was reported, while 3-year overall survival was different in each one (range, 38.6-90\%). Acute and late toxicities were generally low.

Conclusions: Validated probability test together with the use of metabolic imaging may facilitate the clinical diagnosis of cancer in patients with solitary pulmonary nodule. SBRT seems to be a very efficient radical treatment for these subgroups of patients with early stage clinically diagnosed lung cancer, even if more prospective trials are needed.

Keywords: Solitary lung nodule; stereotactic body radiotherapy (SBRT); non-small-cell lung cancer (NSCLC)

Received: 30 May 2021; Accepted: 02 March 2022; Published: 30 September 2022.

doi: 10.21037/asj-21-39

View this article at: https://dx.doi.org/10.21037/asj-21-39

^ ORCID: 0000-0003-1068-5958. 


\section{Introduction}

Lung cancer is the leading cause of cancer death in men and the second one in women worldwide (1). Recently, lung cancer diagnosis has greatly improved due to the wider use of total body computed tomography scan (CT scan) and metabolic diagnostic tools such as 18-F-fluodosossyglucose (18F-FDG) positron emission tomography. Recently, the role of the screening program in high risk patients for lung cancer has been well assessed (2), but concerns on resources, costs, and management of patients with abnormal screening, made its use difficult in the routine. Where the screening program has been correctly applied (3), the use of CT scan seemed to be able to anticipate stage I lung cancer if compared to chest radiography allowing a higher number of surgical radical treatment. This benefit in terms of clinical outcome was also showed in a recent update of the NELSON trial where the lung-cancer mortality for high risk persons was significantly lower among those who underwent volume CT scan screening than among those who did not (4). In the past, the American College of Chest Physicians (ACCP) clinical guidelines tried to identify different categories of lung nodules with different probabilities of malignancy suggesting that transthoracic biopsy or bronchoscopy should be performed even in patients with a high risk of surgical complications (5). However, taking into account the increasing number of new diagnoses of solitary pulmonary nodules, the real issue is to identify when an invasive procedure (such as a biopsy) that could be characterized by severe complications is really needed. Due to age, comorbidities, or poor lung functions, and considering that $2-3.5 \%$ of patients refused this procedure, almost $25 \%$ of patients with single pulmonary nodule will be deemed medically inoperable and consequently remain without pathological confirmation $(6,7)$. Recently, the role of stereotactic body radiotherapy (SBRT) is becoming crucial, particularly in those patients at greater risk of surgical morbidity/mortality or candidate to sublobar resection. For this reason, the optimal therapeutic option (surgery vs. SBRT) should be offered after a multidisciplinary discussion. The role of empirical treatment with SBRT without a pathological confirmation have been increasing in this subset of patients, reaching almost $70 \%$ in some studies $(8,9)$. Data from retrospective series showed that SBRT in patients without a histological confirmation have been encouraging (10-12). The aim of this narrative review is to evaluate the existing international literature about the role of ablative SBRT in treating solitary lung nodules without pathological confirmation.

We present the following article in accordance with the Narrative Review reporting checklist (available at https:// asj.amegroups.com/article/view/10.21037/asj-21-39/rc).

\section{Methods}

A literature search in Medline was performed until April 2021 by one author (ED). Terms used were a combination of "solitary pulmonary nodule", "radiotherapy", "stereotactic body radiotherapy", "pathological confirmation", and "lung". A total of 149 records were identified and screened. English language, full-text articles and presence of data about selection criteria in patients affected by solitary lung nodule not-histologically proven treated with radiation therapy, were inclusion criteria. No time limits were applied. Exclusion criteria were: case reports, abstracts, proceedings from scientific meetings, review and editorials. References listed in the screened articles were also evaluated and cross-referenced to ensure completeness. Studies including sub-cohort of patients treated with and without histological confirmation were included. At the end of the screening procedure, taking into account all the eligibility criteria, 8 studies were selected for the analysis and other 16 were retrieved from references of screened paper. Twentyfour studies were analyzed, and those more relevant will be discussed in our review (Table 1).

\section{Results}

Characteristics of patients enrolled are reported in Table 1. All studies included but two $(9,18)$, are retrospective. In six studies (12-17), only patients without pathological confirmation were included, while other 14 studies compared histologically proven and not populations in terms of clinical outcomes and safety (6,9-11,18,20-27). The studies included in the analysis were published between January 2009 and December 2019. Mean number of patients enrolled in the selected studies was 206 (range, 17-382). In nineteen of the 20 studies, authors declared to perform SBRT. Radiation therapy was delivered using proton or carbon ion just in a single study (22). Conversely, Temming et al. (25) and Wang et al. (16) delivered SBRT using CyberKnife. The median dimension of not histologically proven lesions was 20 (range, 16-28.4) mm. In all studies 18-F fluorodeoxyglucose CT-PET (18FDG) was used during the initial diagnostic assessment for the vast majority of patients (range, 


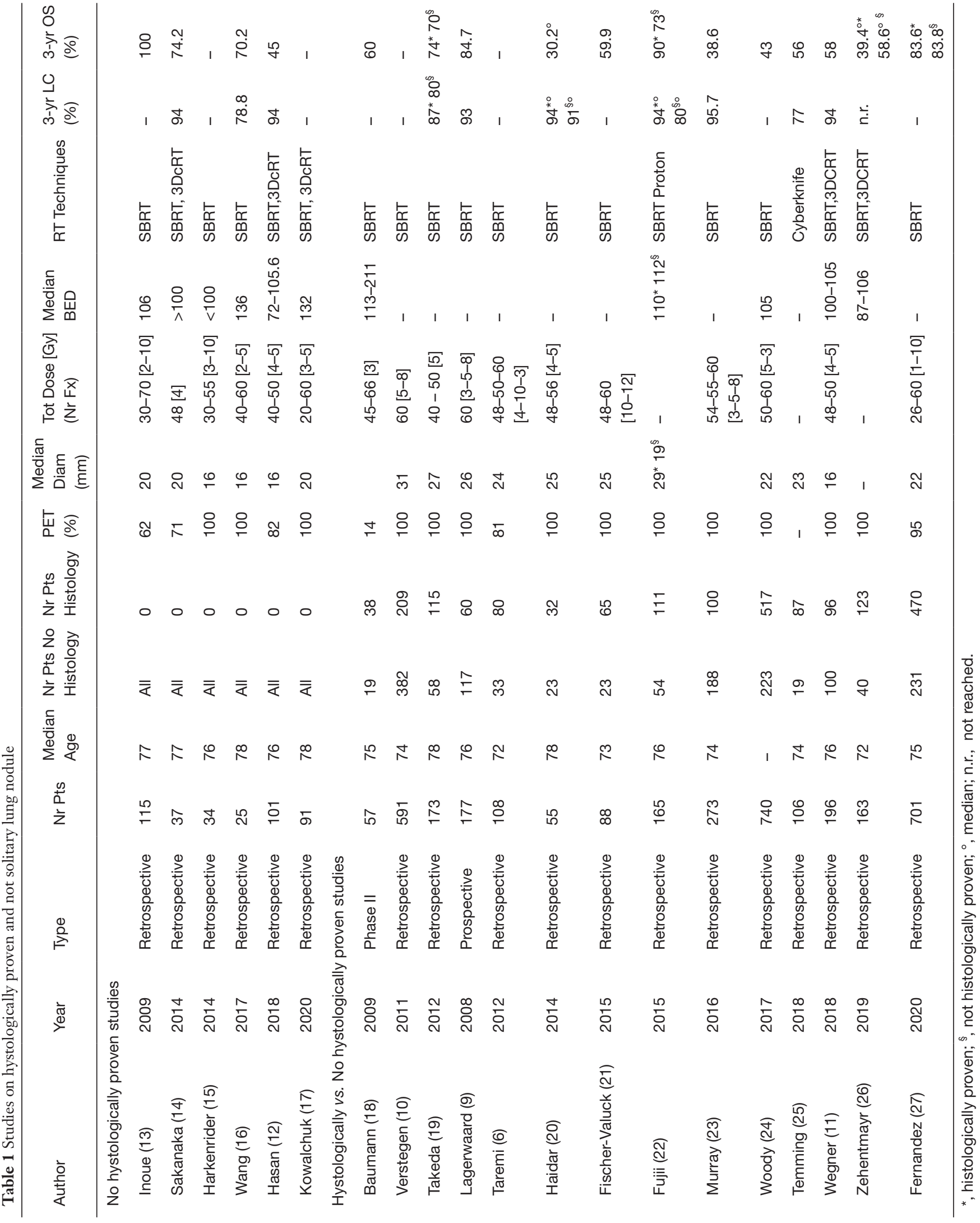


$62-100 \%)$. Main reasons for not proceeding to invasive hystopathological confirmation were: severe COPD, high risk of fatal bleeding, location of the primary tumor, patient' refusal, cardiac comorbidities not suitable for anticoagulant suspension. Furthermore, peripheral lesions were treated more frequently than the central ones. A predictive model for the assessment of cancer probability was used only by Verstegen, Hasan, Sakanaka and Zehentmayr $(10,12,14,26)$, while a combination of clinical and radiological characteristics was used in all the other analyses. Median follow up was 19.7 (range, 13-42) months. Doses delivered were very different, depending on several factors such as tumor dimension and localization, techniques, often also within the same cohort. Radiation therapy doses most frequently delivered were 40-60 Gy in 3-8 fractions using stereotactic techniques. In terms of efficacy, 3 -year local control (reported in $55 \%$ of studies) was higher than $75 \%$, while reported overall survival was more different ranging between $38.6 \%$ and $90 \%$ at three years. Overall toxicity reported was generally low, more than G3 were very rarely described (less than 2\%) (23).

\section{Discussion}

The present review focused on selection criteria in patients addressed to radiation therapy for solitary lung nodules in clinically diagnosed lung cancer.

Patel et al. (28) defined the solitary pulmonary nodule as a radiographic opacity up to 30 millimeters in diameter with at least two-thirds of its margins surrounded by lung parenchyma. As underlined in the evidence-based recommendations by the American College of Chest Physicians (ACCP) published in 2013 (5), the management of solitary lung nodules may strongly vary according to its dimension and radiological features. In the absence of a biopsy, performing adequate instrumental exams and collecting clinical information should help to estimate the probability of cancer. Notably, the recommendations stressed the importance of balancing benefits and harms of the different diagnostic procedures. Indeed, major complications appear to be very low after CT-guided transthoracic biopsy, accounting a risk of almost 5.7\% (29), but the rate increases up to $40 \%$ (30-32) when considering all possible collateral effects. At the same time, the diagnostic yield of biopsies may vary widely (between 64\% and $95 \%$ ), thus exposing some patients to not justified risks without significant benefit.

For patients at high risk for complications (such as pneumothorax in severe COPD patients and fatal bleeding) secondary to diagnostic assessments, some quantitative models for the prediction of cancer probability have been developed. In the Swensen model (33) age, smoking status, history of extrathoracic cancers, nodule diameter, location, and presence of spiculations are combined. Furthermore, the Mayo Clinic model (34) is one of the most extensively validated model in the not-screened population, matching the Swensen model with the use of 18FDG-PET.

The use of those algorithms may help to select patients for SBRT without pathological diagnosis. However, a clear threshold of pre-test probability to treat patients with lung nodules without pathological confirmation using surgery or SBRT is not yet well defined. In the CHEST guidelines the authors stated that an active treatment approach could be reasonable when the pre-test probability of malignancy exceeded $65 \%$. However, this finding is in contrast with the International Association for the Study of Lung Cancer (IALSC) recommendations that suggested a threshold of $85 \%$ (35).

Nowadays, merging information from anatomic and metabolic imaging yielded a higher diagnostic value (36). Louie et al. (37) and Senan et al. (38) added the 18-FDGPET to the probability test and both identified a threshold of $85 \%$. In our review we included also the study of Verstegen (10) that was the internal validation cohort of Louie model. In their report a comparative outcome analysis between proven and not proven patients was conducted. In patients without a pathological diagnosis the Swensen model for cancer probability assessment (33) was used resulting in a mean probability of malignancy equal to 92.5\% (95\% CI: $91.8-93.3 \%$ ); furthermore $93.2 \%$ of these patients had a calculated probability of malignancy that exceeded $80 \%$.

An interesting role of $18 \mathrm{~F}-\mathrm{FDG}-\mathrm{PET}$ in the follow up was then suggested by Hasan et al. (12): indeed, its use may allow a radiologically confirmation of treated lesion, but also it may help the prediction of progression of disease. To date, this approach is not standardized being still under evaluation.

Actually, SBRT is recognized as an efficient and safe alternative to surgery showing high rates of local control in patients affected by early stage non-small cell lung cancer (NSCLC), comparable to surgery, but with a significant inferior morbidity (18).

In 2019, the Empiric Radiotherapy for Lung Cancer Collaborative Group published multi-institutional guidelines for the use of SBRT in patients with lung 
nodules without pathological confirmation (39). The authors focused on staging procedures, tools for predicting cancer probabilities and potential benefits of SBRT. They only analyzed the role of SBRT in treating peripheral lesions, because the central ones are usually candidate to surgery because of the high risk of severe toxicities. They suggested a pre-test threshold of $85 \%$ to candidate patients for local ablative treatment without having pathologically confirmed cancer; furthermore, they recommended moving for a local treatment based on size, radiological imaging and characteristics of the lesions. Authors also emphasized the need of biopsy prior SBRT whenever possible and strongly highlighted the crucial role of the multidisciplinary team in sharing a therapeutic choice in the context of "tailored" medicine.

The role of the multidisciplinary discussion on patients with suspicious early-lung cancer could be a point of strength requested by the main international guidelines, but the selection criteria are so variable between different Institutions, as observed in the studies collected in this review. Indeed, almost all studies reported not specific inclusion criteria for patients candidate to local "empiric" treatment. Moreover, no pre-test threshold was usually described. Only few authors $(10,12,14,26)$ described the predictive model of cancer probability.

The role of predictive model and guidelines, as previously described, should help clinicians to weighting comorbidities and their life expectancy, in order to identify those patients candidate to invasive procedures for a pathological diagnosis and consequently, to local ablative treatment (surgery or SBRT).

In the comparative studies, patients without histological confirmation had smaller tumor diameter than those with pathological specimen $(10,11,22)$. In Verstegen et al. (10), 591 patients were treated with SBRT with significant results in terms of local control (LC). No differences between both cohorts and no factors significantly correlate to overall survival (OS) after multivariate analysis. A subgroup analysis was then performed to assess differences in terms of clinical stage (T1 vs. T2) between the two groups, but no difference in OS neither in LC was found. Importantly, Inoue et al. found a statically significant difference $(\mathrm{P}<0.0005)$ in terms of OS in patients with a tumor size (diameter) of 5-20 mm $(\mathrm{n}=58)$ vs. 21-45 mm ( $\mathrm{n}=57)$ (13). Some hypothesis could be made to understand the lack of difference in OS related to dimension, as reported in Verstegen et al. and Inoue et al. $(10,13)$. In the Japanese cohort, the median follow-up was quite short (14 months), also including 11 patients with a follow up shorter than 4 months. For these reasons, definitive conclusions about OS are difficult, not being possible to completely exclude the option that benign lesions were treated in the group with a median smaller nodule dimension. Similar results were also reported in Sakanaka et al. (14), where patients with clinical T1a stage had a significantly higher OS and PFS than those presenting clinical T1b/T2a tumors. On the other hand, no differences in terms of LC were found. The same authors also reported a crude rate of relapse equal to $41 \%$, occurring 36 months after treatment. It should be noted that the vast majority of the studies included in our review reported a median FUP inferior than 24 months, thus probably underestimating the overall incidence of relapse and cancer related death.

Clinical differences are very clear in the inclusion criteria used in the different studies. Hasan et al. (12) included patients mostly aged $>70$ with a smoking history characterized by $>50$ pack-year, oxygen therapy dependent and with a median predicted forced expiratory volume equal to $42 \%$. This cohort of patients was not suitable for surgery and usually diagnosed by regular CT scan during the management of chronic obstructive pulmonary disease. Conversely, in the series of Verstegen et al. (10) patients were mostly defined as operable and diagnosed by the national screening program. These characteristics necessarily reflected the different results in terms of OS and may explain the low rate of OS in the paper published by Hasan et al. (12).

In elderly patients, SBRT was evaluated by Wang et al. (16). In a small series of 25 patients with more than 75 years and usually not suitable for to surgery (76\%) due to comorbidities, 1-, 3- and 5-year local control and cancer specific survival were $100 \%, 78.8 \%, 65.7 \%$ and $100 \%$, $81.3 \%$, and $67.0 \%$, respectively. Acute and late toxicity was very low. Similar results were reported in most of the studies analyzed (see Table 1) where 3-year local control and OS varied between $80-94 \%$, and $54-90 \%$, respectively.

Elderly patients with multiple comorbidities, such as poor pulmonary function, could be at high risk of complications when treated by ablative SBRT, causing an increased and not justified mortality. However, poor pulmonary functions seemed not to be associated to increased mortality or toxicity in patients treated with SBRT for early stage NSCLC (40). Verstegen et al. and Takeda et al. then confirmed these findings $(10,19)$. As reported in Shaik et al. (41), the different results in terms of efficacy could be potentially affected by the presence of benign lesions in the cohorts of patients analyzed, 
particularly when nodules' diameter was smaller than $2 \mathrm{~cm}$. At univariate analysis, cancer specific survival and OS were better in patients without histological confirmation as reported in the SEER database series. Regarding these findings, Verstegen et al. (10) reported a 3-year local control superior than $90 \%$ with local failures observed in only 10 and 18 patients with a pathological or clinical diagnosis, respectively. In the meanwhile, taking into account that benign granulomas were considered unlikely to shrink after SABR, the proportion of patients with stable disease after SBRT in the not pathologically confirmed cohort were $3.5 \%$ and $3.7 \%$ at 6 and 12 months, very similar to those with pathological confirmation.

Also the presence of previous cancer diagnosis may help in decision-making, but sometimes it could led to confounding results: in Verstegen et al., 34\% of total patients presented a previous history of cancer and approximately $50 \%$ of them had previously been treated for lung cancer (10).

Other confounding factors could be the presence of lesions other than NSCLC: indeed it is estimated that $4-12 \%$ of patients with solid solitary pulmonary nodule may have a SCLC diagnosis (42), so that it could be questionable if a "radical" treatment with SBRT should be used.

When choosing the optimal radiation treatment, the absence of pathological confirmation plays an important role: in Woody et al. (24), despite the selection bias, an increased rate of local failure was reported in patients with squamous cell carcinoma treated with SBRT. So, the authors advocate different schedules depending on different histology.

Finally, one of the main limits of all the studies selected was the long time of accrual that may have a crucial impact on the different radiation therapy schedules. Recently, several authors $(40,43)$ supported the important role of biologically equal dose (BED) ${ }_{10}>100$ Gray (Gy) to improve OS and local control in NSCLC treated with SBRT. However, in the studies analyzed (when reported) median $\mathrm{BED}_{10}$ was usually superior to $100 \mathrm{~Gy}$, but many patients received inferior doses. In the cohort of Zehentmayr et al. (26) the minimum $\mathrm{BED}_{10}$ used was $15 \%$ lower, while only $15 \%$ of patients had a $\mathrm{BED}_{10}<100$ Gy in Inoue et al. (13).

Our review is characterized by several limitations. First, the vast majority of international literature was characterized by a significantly different selection criteria and treatments delivered, probably due to the long period of accrual and the retrospective nature of each study. Second, clinical outcome reported were very different, due to several reasons such as the different populations analyzed in terms of comorbidities and performance status or the different tumor features. Similar limitations were encountered in the comparative studies (Table 1), even if the cohorts were apparently more homogenous. Notably, results in terms of efficacy and clinical outcomes were similar between comparative and not-comparative studies, while toxicities were usually very low.

\section{Conclusions}

In conclusion, the introduction of validated probability test together with the wider diffusion of metabolic imaging such as 18 FDG PET CT scan may facilitate the clinical diagnosis of cancer in patients with solid solitary pulmonary nodules. Furthermore, clinical outcomes following SBRT seem to be similar in patients either with or without a pathology-proven diagnosis of early stage lung cancer. Prospective well-designed clinical trials are needed in this subset of patients so that stronger recommendations may be proposed in patients with not proven solid solitary pulmonary nodule.

\section{Acknowledgments}

Funding: None.

\section{Footnote}

Provenance and Peer Review: This article was commissioned by the Guest Editors (Duilio Divisi and Roberto Crisci) for the series "Solitary Pulmonary Nodule" published in $A M E$ Surgical fournal. The article has undergone external peer review.

Reporting Checklist: The authors have completed the Narrative Review reporting checklist. Available at https:// asj.amegroups.com/article/view/10.21037/asj-21-39/rc

Peer Review File: Available at https://asj.amegroups.com/ article/view/10.21037/asj-21-39/prf

Conflicts of Interest: All authors have completed the ICMJE uniform disclosure form (available at https://asj.amegroups. com/article/view/10.21037/asj-21-39/coif). The series "Solitary Pulmonary Nodule" was commissioned by the editorial office without any funding or sponsorship. EDA 
reports personal payments for lectures from Nestle', MSD, Astra Zeneca, and support for attendance meeting. $\mathrm{AB}$ reports payment for advisory board, manuscript writing, educational events, and conference presentations from ATREA ZENECA, payment for conference presentations from MSD and ASTELLAS, support for attending meetings and/or travel from ASTRA ZENECA, MSD, ASTELLAS, IBSEN and TAKEDA. LR reports honoraria for presentations from ASTRA ZENECA and MSD. The authors have no other conflicts of interest to declare.

Ethical Statement: The authors are accountable for all aspects of the work in ensuring that questions related to the accuracy or integrity of any part of the work are appropriately investigated and resolved.

Open Access Statement: This is an Open Access article distributed in accordance with the Creative Commons Attribution-NonCommercial-NoDerivs 4.0 International License (CC BY-NC-ND 4.0), which permits the noncommercial replication and distribution of the article with the strict proviso that no changes or edits are made and the original work is properly cited (including links to both the formal publication through the relevant DOI and the license). See: https://creativecommons.org/licenses/by-nc-nd/4.0/.

\section{References}

1. Ferlay J, Soerjomataram I, Ervik M, et al. GLOBOCAN 2012 v1.0, cancer incidence and mortality worldwide: IARC cancer base no. 11. International Agency for Research on Cancer, Lyon.

2. Aberle DR, DeMello S, Berg CD, et al. Results of the two incidence screenings in the National Lung Screening Trial. N Engl J Med 2013;369:920-31.

3. National Lung Screening Trial Research Team, Church TR, Black WC, et al. Results of initial low-dose computed tomographic screening for lung cancer. $\mathrm{N}$ Engl J Med 2013;368:1980-91.

4. de Koning HJ, van der Aalst CM, de Jong PA, et al. Reduced Lung-Cancer Mortality with Volume CT Screening in a Randomized Trial. N Engl J Med 2020;382:503-13.

5. Gould MK, Donington J, Lynch WR, et al. Evaluation of individuals with pulmonary nodules: when is it lung cancer? Diagnosis and management of lung cancer, 3rd ed: American College of Chest Physicians evidence-based clinical practice guidelines. Chest 2013;143:e93S-e120S.
6. Taremi M, Hope A, Dahele M, et al. Stereotactic body radiotherapy for medically inoperable lung cancer: prospective, single-center study of 108 consecutive patients. Int J Radiat Oncol Biol Phys 2012;82:967-73.

7. Lathan CS, Neville BA, Earle CC. The effect of race on invasive staging and surgery in non-small-cell lung cancer. J Clin Oncol 2006;24:413-8.

8. Rutter CE, Corso CD, Park HS, et al. Increase in the use of lung stereotactic body radiotherapy without a preceding biopsy in the United States. Lung Cancer 2014;85:390-4.

9. Lagerwaard FJ, Haasbeek CJ, Smit EF, et al. Outcomes of risk-adapted fractionated stereotactic radiotherapy for stage I non-small-cell lung cancer. Int J Radiat Oncol Biol Phys 2008;70:685-92.

10. Verstegen NE, Lagerwaard FJ, Haasbeek CJ, et al. Outcomes of stereotactic ablative radiotherapy following a clinical diagnosis of stage I NSCLC: comparison with a contemporaneous cohort with pathologically proven disease. Radiother Oncol 2011;101:250-4.

11. Wegner RE, Ahmed N, Hasan S, et al. SBRT for early stage lung cancer: outcomes from biopsy-proven and empirically treated lesions. Lung Cancer Manag 2018;7:LMT01.

12. Hasan S, Colonias A, Mickus T, et al. Image-based management of empiric lung stereotactic body radiotherapy (SBRT) without biopsy: Predictors from a 10-year single institution experience. Thorac Cancer 2018;9:699-706.

13. Baumann P, Nyman J, Hoyer M, et al. Outcome in a prospective phase II trial of medically inoperable stage I non-small-cell lung cancer patients treated with stereotactic body radiotherapy. J Clin Oncol 2009;27:3290-6.

14. Inoue $\mathrm{T}$, Shimizu S, Onimaru R, et al. Clinical outcomes of stereotactic body radiotherapy for small lung lesions clinically diagnosed as primary lung cancer on radiologic examination. Int J Radiat Oncol Biol Phys 2009;75:683-7.

15. Sakanaka K, Matsuo Y, Nagata Y, et al. Safety and effectiveness of stereotactic body radiotherapy for a clinically diagnosed primary stage I lung cancer without pathological confirmation. Int J Clin Oncol 2014;19:814-21.

16. Wang Z, Li AM, Gao J, et al. Clinical outcomes of CyberKnife stereotactic radiosurgery for elderly patients with presumed primary stage I lung cancer. Transl Lung Cancer Res 2017;6:6-13.

17. Harkenrider MM, Bertke MH, Dunlap NE. Stereotactic body radiation therapy for unbiopsied early-stage lung 
cancer: a multi-institutional analysis. Am J Clin Oncol 2014;37:337-42.

18. Kowalchuk RO, Waters MR, Baliga S, et al. Stereotactic body radiation therapy for empirically treated hypermetabolic lung lesions: a singleinstitutional experience identifying the Charlson score as a key prognostic factor. Transl Lung Cancer Res 2020;9:1862-72.

19. Takeda A, Kunieda E, Sanuki N, et al. Stereotactic body radiotherapy (SBRT) for solitary pulmonary nodules clinically diagnosed as lung cancer with no pathological confirmation: comparison with non-small-cell lung cancer. Lung Cancer 2012;77:77-82.

20. Haidar YM, Rahn DA 3rd, Nath S, et al. Comparison of outcomes following stereotactic body radiotherapy for non-small cell lung cancer in patients with and without pathological confirmation. Ther Adv Respir Dis 2014;8:3-12.

21. Fischer-Valuck BW, Boggs H, Katz S, et al. Comparison of stereotactic body radiation therapy for biopsy-proven versus radiographically diagnosed early-stage non-small lung cancer: a single-institution experience. Tumori 2015;101:287-93.

22. Fujii O, Demizu Y, Hashimoto N, et al. Particle therapy for clinically diagnosed stage I lung cancer: comparison with pathologically proven non-small cell lung cancer. Acta Oncol 2015;54:315-21.

23. Murray L, Ramasamy S, Lilley J, et al. Stereotactic Ablative Radiotherapy (SABR) in Patients with Medically Inoperable Peripheral Early Stage Lung Cancer: Outcomes for the First UK SABR Cohort. Clin Oncol (R Coll Radiol) 2016;28:4-12.

24. Woody NM, Stephans KL, Andrews M, et al. A Histologic Basis for the Efficacy of SBRT to the lung. J Thorac Oncol 2017;12:510-9.

25. Temming S, Kocher M, Stoelben E, et al. Risk-adapted robotic stereotactic body radiation therapy for inoperable early-stage non-small-cell lung cancer. Strahlenther Onkol 2018;194:91-7.

26. Zehentmayr F, Sprenger M, Rettenbacher L, et al. Survival in early lung cancer patients treated with high dose radiotherapy is independent of pathological confirmation. Thorac Cancer 2019;10:321-9.

27. Fernandez C, Grills IS, Ye H, et al. Stereotactic Image Guided Lung Radiation Therapy for Clinical Early Stage Non-Small Cell Lung Cancer: A Long-Term Report From a Multi-Institutional Database of Patients Treated With or Without a Pathologic Diagnosis. Pract Radiat Oncol 2020;10:e227-37.

28. Patel VK, Naik SK, Naidich DP, et al. A practical algorithmic approach to the diagnosis and management of solitary pulmonary nodules: part 1 : radiologic characteristics and imaging modalities. Chest 2013;143:825-39.

29. Heerink WJ, de Bock GH, de Jonge GJ, et al. Complication rates of CT-guided transthoracic lung biopsy: meta-analysis. Eur Radiol 2017;27:138-48.

30. Boskovic T, Stanic J, Pena-Karan S, et al. Pneumothorax after transthoracic needle biopsy of lung lesions under CT guidance. J Thorac Dis 2014;6 Suppl 1:S99-S107.

31. Wiener RS, Schwartz LM, Woloshin S, et al. Populationbased risk for complications after transthoracic needle lung biopsy of a pulmonary nodule: an analysis of discharge records. Ann Intern Med 2011;155:137-44.

32. Yildirim E, Kirbas I, Harman A, et al. CT-guided cutting needle lung biopsy using modified coaxial technique: factors effecting risk of complications. Eur J Radiol 2009;70:57-60.

33. Swensen SJ, Silverstein MD, Edell ES, et al. Solitary pulmonary nodules: clinical prediction model versus physicians. Mayo Clin Proc 1999;74:319-29.

34. Herder GJ, van Tinteren H, Golding RP, et al. Clinical prediction model to characterize pulmonary nodules: validation and added value of $18 \mathrm{~F}$-fluorodeoxyglucose positron emission tomography. Chest 2005;128:2490-6.

35. Field JK, Smith RA, Aberle DR, et al. International association for the study of lung cancer computed tomography screening workshop 2011 report. J Thorac Oncol 2012;7:10-9.

36. Kim SK, Allen-Auerbach M, Goldin J, et al. Accuracy of PET/CT in characterization of solitary pulmonary lesions. J Nucl Med 2007;48:214-20.

37. Louie AV, Senan S, Patel P, et al. When is a biopsyproven diagnosis necessary before stereotactic ablative radiotherapy for lung cancer?: A decision analysis. Chest 2014;146:1021-8.

38. Senan S, Paul MA, Lagerwaard FJ. Treatment of earlystage lung cancer detected by screening: surgery or stereotactic ablative radiotherapy? Lancet Oncol 2013;14:e270-4.

39. Berman AT, Jabbour SK, Vachani A, et al. Empiric Radiotherapy for Lung Cancer Collaborative Group multi-institutional evidence-based guidelines for the use of empiric stereotactic body radiation therapy for non-small cell lung cancer without pathologic confirmation. Transl Lung Cancer Res 2019;8:5-14. 
40. Guckenberger M, Andratschke N, Alheit H, et al. Definition of stereotactic body radiotherapy: principles and practice for the treatment of stage I non-small cell lung cancer. Strahlenther Onkol 2014;190:26-33.

41. Shaikh T, Churilla TM, Murphy CT, et al. Absence of Pathological Proof of Cancer Associated with Improved Outcomes in Early-Stage Lung Cancer. J Thorac Oncol 2016;11:1112-20.

doi: 10.21037/asj-21-39

Cite this article as: D'Angelo E, Lauro C, Rubino L, Bruni A. Non-invasive approach to treat primary solid solitary pulmonary nodule: a narrative review by the radiation oncologist perspective. AME Surg J 2022;2:26.
42. Kreisman H, Wolkove N, Quoix E. Small cell lung cancer presenting as a solitary pulmonary nodule. Chest 1992;101:225-31.

43. Moustakis C, Blanck O, Ebrahimi Tazehmahalleh F, et al. Planning benchmark study for SBRT of early stage NSCLC : Results of the DEGRO Working Group Stereotactic Radiotherapy. Strahlenther Onkol 2017;193:780-90. 